
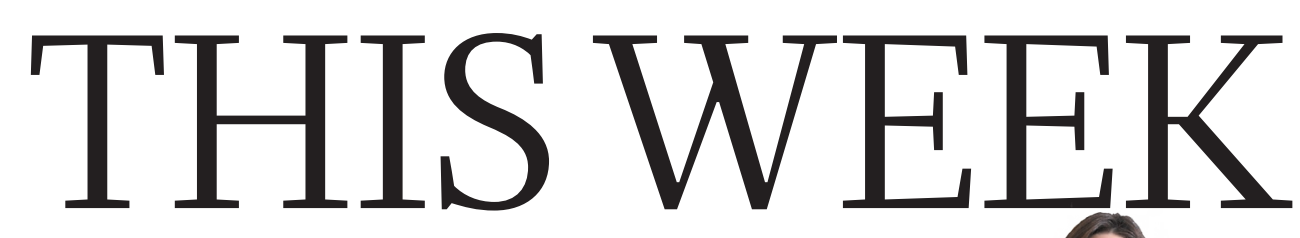

EDITORIALS

CANCER Moonshot project gets researchers on board $\mathbf{p . 4 1 4}$
WORLD VIEW Track small acts of aggression to fix science $\mathbf{p . 4 1 5}$
BOTANY Plant bleeding

draws predators for protection $\mathbf{p . 4 1 6}$

\title{
Anticipating artificial intelligence
}

Concerns over AI are not simply fear-mongering. Progress in the field will affect society

profoundly, and it is important to make sure that the changes benefit everyone.

I n January, the Information Technology and Innovation Foundation in Washington DC gave its annual Luddite Award to "a loose coalition of scientists and luminaries who stirred fear and hysteria in 2015 by raising alarms that artificial intelligence (AI) could spell doom for humanity".

The winners - if that is the correct word - included pioneering inventor Elon Musk and physicist Stephen Hawking.

In January last year, both signed an open letter that argued for research and regulatory and ethical frameworks to ensure that AI benefits humanity and to guarantee that "our AI systems must do what we want them to do". Hardly "fear and hysteria".

As AI converges with progress in robotics, cloud computing and precision manufacturing, tipping points will arise at which significant technological changes are likely to occur very quickly. Crucially, advances in robot vision and hearing, combined with AI, are allowing robots to better perceive their environments. This could lead to an explosion of intelligent robot applications - including those in which robots will work closely with humans.

Even academic debate on AI has tended to be polarized between sceptics and fanciful futurists. Yet there is an emerging middle-ground consensus that AI research is poised to have profound impacts on society. For those who remain sceptical that progress is imminent, bear in mind that Google, Toyota, Facebook, Microsoft and other companies are together pouring billions of dollars into AI and robotics research, which they see as the next frontier for profits (see page 422). Efforts to accelerate research must be accompanied by safeguards against the potential pitfalls of these powerful technologies.

Stuart Russell, a computer scientist at the University of California, Berkeley, who is well known for his deeply sceptical views on overexpectations of technological progress, is convinced that it is time to assess and mitigate potential risks. "Several technologies are reaching the level where they could be developed in potentially harmful directions," says Russell, who was a driving force behind the open letter signed by Musk and Hawking.

So, what are the risks? Machines and robots that outperform humans across the board could self-improve beyond our control and their interests might not align with ours. This extreme scenario, which cannot be discounted, is what captures most popular attention. But it is misleading to dismiss all concerns as worried about this.

There are more immediate risks, even with narrow aspects of AI that can already perform some tasks better than humans can. Few foresaw that the Internet and other technologies would open the way for mass, and often indiscriminate, surveillance by intelligence and law-enforcement agencies, threatening principles of privacy and the right to dissent. AI could make such surveillance more widespread and more powerful.

Then there are cybersecurity threats to smart cities, infrastructure and industries that become overdependent on $\mathrm{AI}$ - and the all too clear threat that drones and other autonomous offensive weapons systems will allow machines to make lethal decisions alone.

The first wave of AI is already beginning to pervade our lives inconspicuously, from speech recognition and search engines to image classification. Self-driving cars and applications in health care are within sight, and subsequent waves could transform vast sectors of the economy, science and society. These could offer substantial benefits - but to whom?

Historically, automation in agriculture and industry has caused

mass extinctions of jobs and led to profound "As AI converges societal changes - including rapid urbanizawith progress tion. But job losses have typically been more in robotics, than compensated for by jobs created in the significant technological changes are likely to occur very quickly." service and high-tech industries.

Many experts worry that AI and robots are now set to replace repetitive but skilled jobs that had been thought to be beyond machines, and it's not obvious where new jobs would come from. The spectre of permanent mass unemployment, and increased inequality that hits hardest along lines of class, race and gender, is perhaps all too real.

A society dependent on AI could yield broad benefits if increased wealth resulting from gains in productivity is shared. But currently, most such benefits are concentrated in companies and the capital of their shareholders - including the infamous $1 \%$.

It is crucial that progress in technology is matched by solid, wellfunded research to anticipate the scenarios it could bring about, and to study possible political and economic reforms that will allow those usurped by machinery to contribute to society. If that is a Luddite perspective, then so be it.

\section{On a downer}

\section{The United Nations has chosen to keep the war on drugs going - but it can't win.}

$\mathrm{R}$ eaders of the Los Angeles Times last week received some unexpected news about a major shift in the attitude of the United Nations towards the decriminalization of cannabis. According to the paper, the UN Office on Drugs and Crime (UNODC) was set to announce a more tolerant approach at a major meeting in New York City. But although the meeting was real, the policy shift was not. The announcement was a hoax, and pointedly timed for 20 April (' $4 / 20$ '), a day on which cannabis users celebrate and promote their choice. The scam even included a well-constructed fake press release 